\title{
A moça tecelã: um texto instigante
}

DOI: http://dx.doi.org/10.21165/el.v48i2.2253

\author{
Nelyse A. Melro Salzedas ${ }^{1}$ \\ Rivaldo Alfredo Paccola ${ }^{2}$
}

\section{Resumo}

A construção do texto de Colasanti (2012), "A moça tecelã", versa sobre tecer um texto, o qual estamos tomando como objeto de análise da construção textual, cujo desenho é traçado pelo movimento das mãos da artífice manipulando a lançadeira, o tear, as linhas que constroem a escrita, a partir de seu grau zero, em decorrência da sua desconstrução. 0 fazer de um texto instigante como o de Marina Colasanti, apresentado no título, demanda uma série de leituras teóricas para acompanhar seu desenho construtor. Em vista disso, o objetivo deste artigo é analisar o fazer do texto. "Tecer era tudo que fazia. Tecer era tudo o que queria fazer [...] e tecendo ela própria trouxe o tempo.". Esse enunciado de Colasanti (2012, p. 12) pontua a construção de um texto, no qual cada laçada é um fonema e cada ponto construído é um sentido. Assim, recorremos a Genette (2010, p. 7) que investiga a produção do texto através do palimpsesto. O que é o palimpsesto? Para ele, é "um pergaminho cuja primeira inscrição foi raspada para se traçar outra, que não a esconde de fato, de modo que se pode lê-la por transparência, o antigo sob o novo.". Essa leitura do antigo sob o novo foi feita no texto de Colasanti (2012), ilustrando a teoria de Genette, quanto à criação do texto. Desse modo, nos permitiu navegar pelo hipertexto e pelo hipotexto, construções da transtextualidade, que podem ser feitas pela transformação e pela imitação. Estudamos Genette também num texto de Borges, uma vez que o mesmo propõe que sempre houve um só texto e um só autor, pensando no hipertexto e no hipotexto. Essa estratégia de leitura permite que o texto não seja contado, mas ele se conte por si mesmo. Com as sucessivas raspagens, o leitor vai encontrar a origem, o texto primígeno; nesse percurso, vai perceber a transtextualidade, um texto entrando em outro texto.

Palavras-chave: hipertexto; hipotexto; palimpsesto; leitura palimpsestuosa.

1 Universidade Estadual Paulista "Júlio de Mesquita Filho" (UNESP), Bauru, São Paulo, Brasil; nelysesalzedas@yahoo.com.br; http://orcid.org/0000-0002-5859-6391

2 Universidade Federal dos Vales do Jequitinhonha e Mucuri (UFVJM), Diamantina, São Paulo, Brasil; rivapaccola@terra.com.br; http://orcid.org/0000-0002-2792-2748 


\title{
A moça tecelã: an inspiring text
}

\begin{abstract}
The construction of the text by Colasanti (2012), "A moça tecelã", is about making a text, which we are taking as an object of analysis of textual construction, whose design is traced by the movement of the hands of the artificer manipulating the shuttle, the loom, the threads that construct the writing, from its degree zero, as a result of its deconstruction. The making of a provocative text such as that of Marina Colasanti, presented in the title, demands a series of theoretical readings to accompany its building design. In view of this, the purpose of this article is to analyze the text construction. "Weaving was everything she did. Weaving was all she wanted to do [...] and weaving brought herself the time." This statement of Colasanti $(2012$, p.12) marks the construction of a text, where each loop is a phoneme and each stitch constructed is a sense. Thus, we turn to Genette $(2010, p .7)$ that investigates the production of the text through the palimpsest. What is the palimpsest? For him, it is "a parchment whose first inscription was scraped to trace another, which does not conceal it in fact, so that one can read it by transparency, the old under the new." This reading of the old under the new was made in the text of Colasanti (2012), illustrating Genette's theory, regarding the creation of the text. In this way, it allowed us to navigate the hypertext and the hypotext, constructions of transtextuality, which can be made by transformation and imitation. We study Genette also in a text by Borges, because he proposes that there was always only one text and only one author, thinking about the hypertext and the hypotext. This reading strategy allows the text not to be told, but it tells itself. With the successive scraping, the reader will find the origin, the primitive text; in this course, will perceive transtextuality, a text entering another text.
\end{abstract}

Keywords: hypertext; hipotext; palimpsest; palimpsescent reading.

\section{Introdução}

Enrique Bernárdez (1982), em Introducción a la linguística del texto, busca a definição de texto arrolando onze variações de diversos teóricos da linguística, procurando sublinhar a atividade - o caráter comunicativo; a intenção do falante, situação - o caráter pragmático; e ainda normas regentes da estrutura textual, de modo que "texto é a unidade linguística comunicativa fundamental, produto da atividade verbal humana, que sempre tem caráter social [...]." (op. cit., p. 85).

Este artigo retoma a inquietação de Bernárdez presente na supracitada obra. Assim, recorremos ao texto: sua produção e sua criação. Para este exercício linguístico, o texto escolhido foi o de Colasanti (2012), "A moça tecelã", e juntamos a ele o adjetivo "instigante". 
Nas nossas pesquisas sobre texto, após Bernárdez, aproximamo-nos de Austin e Searle para discutir os atos de fala; agora, recorremos a Genette (1982), especificamente à obra Palimpsestes: la littérature au second degré, a fim de tentar chegar à produção e à criação do texto, no dizer de Philippe Lejeune, "leitura palimpsestuosa".

Numa primeira folheada, trabalhamos com a problemática da criação, sob o ponto de vista do palimpsesto que, segundo Genette (1982, 2ª contracapa, tradução nossa), seria "um pergaminho cuja primeira inscrição foi raspada para se traçar outra, que não a esconde de fato, de modo que se pode lê-la por transparência, o antigo sob o novo." ${ }^{3}$ Completa Genette (id. ib., tradução nossa), "assim, no sentido figurado, entenderemos por palimpsestos (mais literalmente: hipertextos) todas as obras derivadas de uma obra anterior, por transformação ou por imitação [...] um texto pode sempre ler um outro."4.

Genette (1982) tem por objeto a transtextualidade que ele define como tudo o que se coloca em relação, manifesta ou secreta, com outros textos. Em suas buscas acabou enumerando cinco tipos de relações transtextuais, organizadas numa ordem crescente de abstração, implicação e globalidade. O primeiro tipo dessas relações apontadas por Genette é a intertextualidade, entendida no sentido que Kristeva (1969, p. 85, tradução nossa) atribui a ela, o texto como assimilação de um outro texto: "todo texto se constrói como um mosaico de citações, todo texto é a absorção e transformação de um outro texto"5; por isso, Genette (1982, p. 8, tradução nossa) define o processo "como uma relação de co-presença entre dois ou vários textos, isto é, essencialmente, e o mais frequentemente, como presença efetiva de um texto em um outro." ${ }^{6}$

Pela intertextualidade, há expansão do texto, progressão trilhada na influência de obras anteriores, uma rede de correlações entre os textos capaz de revelar as marcas que atestam a presença do outro; é o resultado de um imbricamento de textos. Todo texto é constituído de sedimentações autorais diversas e não há como despi-lo dessas marcas que transparecem a presença do outro, pois todo texto está permeado de textos anteriores.

3 No original: "[...] un parchemin dont on a gratté la première inscripcion pour lui en substituer une autre, mais où cette opération n'a pas irrémédiablement effacé le texte primitive, en sorte qu'on peut y lire l'ancien sous le nouveau, comme par transparence".

4 No original: "Cet état de choses montre, au figuré, [...] j'entends ici par hypertextes toutes les œuvres dérivées d'une œuvre antérieure, par transformation, [...] Un texte peut toujours en lire un autre $[\ldots]^{\prime \prime}$.

5 No original: "tout texte se construit comme mosaique de citations, tout texte est absorption et transformation d'un autre texte".

6 No original: "une relation de coprésence entre deux ou plusieurs textes, c'est-à-dire, eidétiquement et le plus souvent, par la présence effective d'un texte dans un autre". 
Genette (2010) também se reporta às observações de Riffaterre (1979, p. 68) na sua abordagem sobre o intertexto como "a percepção pelo leitor de relações entre uma obra e outra e outras, que a precederam ou a sucederam", quando chega a identificar a intertextualidade. No entanto, ainda que reconheça a amplitude do conceito de intertextualidade elaborado por Riffaterre, Genette (2010, p. 15) alerta para o fato de essa ampliação teórica se dar apenas no plano de "microestruturas semântico-estilísticas, no nível da frase, do fragmento ou do texto breve, geralmente poético.".

O segundo tipo é composto pela relação que, no conjunto de uma obra literária, o texto propriamente dito mantém com o que se pode denominar seu paratexto que reúne, por exemplo: título, subtítulo, intertítulos, prefácios, posfácios, advertências, prólogos, etc.; notas marginais, de rodapé, de fim de texto; epígrafes; ilustrações; release, orelha, capa e muitos outros tipos de sinais acessórios, autógrafos ou alógrafos, que, no entender de Genette (2010, p. 15), "fornecem ao texto um aparato (variável) e por vezes um comentário, oficial ou oficioso, do qual o leitor, o mais purista e o menos vocacionado à erudição externa, nem sempre pode dispor tão facilmente como desejaria e pretende."

Metatextualidade é o terceiro tipo de transcendência textual apontado por Genette (2010, p. 17), conceituado como sendo um comentário que realiza a relação de um texto a outro sem que necessariamente se faça citação ou invocação ou, até mesmo, sem nomeá-lo: "é assim que Hegel, na Fenomenologia do espírito, evoca, alusiva e silenciosamente, o sobrinho de Rameau.".

Antes de apresentar o quarto tipo de relação transtextual, Genette (2010) antecipa o quinto uma vez que, segundo sua justificativa, é com o quarto que ele se ocupa na sua abordagem palimpsesta. Assim, o quinto tipo de relação transtextual é denominado de arquitextualidade:

\footnotetext{
Uma relação completamente silenciosa, que, no máximo, articula apenas uma menção paratextual (titular, como em Poesias, Ensaios, o Roman de la Rose, etc., ou mais frequentemente, infratitular: a indicação Romance, Narrativa, Poemas, etc., que acompanha o título, na capa), de caráter puramente taxonômico. Essa relação pode ser silenciosa, por recusa de sublinhar uma evidência, ou, ao contrário, para recusar ou escamotear qualquer taxonomia. (GENETTE, 2010, p. 17)
}

Seguindo a ordem de Genette (2010, p. 18), agora destacamos o quarto tipo de relação transtextual que ele denomina de hipertextualidade, a qual conceitua como "toda relação que une um texto B (que chamarei hipertexto) a um texto anterior A (que, naturalmente, chamarei hipotexto) do qual ele brota de uma forma que não é a do comentário.". Esse procedimento pode gerar uma derivação de ordem descritiva e intelectual, como uma 
derivação por transformação. Neste caso, B não fala nada de A, mas não pode existir como tal sem A, do qual ele resulta. O autor exemplifica essa relação hipertextual referindo-se às seguintes obras:

\begin{abstract}
A Eneida e Ulisses são, sem dúvida, em diferentes graus e certamente a títulos diversos, dois (entre outros) hipertextos de um mesmo hipotexto: a Odisséia, naturalmente. Como se vê por esses exemplos, o hipertexto é mais frequentemente considerado como uma obra "propriamente literária" do que o metatexto - pelo simples fato, entre outros, de que, geralmente derivado de uma obra de ficção (narrativa ou dramática), ele permanece obra de ficção, e, como tal, aos olhos do público entra por assim dizer automaticamente no campo da literatura. (GENETTE, 2010, p. 18).
\end{abstract}

O mecanismo derivativo que implica a essas duas obras, Eneida e Ulisses, ao mesmo hipotexto, a Odisseia, Genette (2010, p. 19) chama de "operação transformadora", por meio da qual Eneida e Ulisses se distinguem entre si: em Ulisses "uma transformação simples, ou direta: aquela que consiste em transportar a ação da Odisseia para Dublin do século XX". Já a transformação que resulta na criação de Eneida derivativa da Odisséia, Genette (id., ib.) diz ser mais complexa e indireta porque: "Virgílio [...] conta uma outra história completamente diferente [...], mas, para fazê-lo, se inspira no tipo [...] estabelecido por Homero na Odisséia [...], ou, como se tem dito durante séculos, imita Homero.". De modo que a imitação é apresentada por Genette (id., ib.) também como uma transformação, porém, de um procedimento mais complexo uma vez que "exige a constituição prévia de um modelo de competência genérico [...] extraído dessa performance única que é a Odisséia [...] e capaz de gerar um número indefinido de performances miméticas.".

Em vista disso, Genette (2010, p. 15) chama de transtextualidade: "O intertexto", escreve ele, por exemplo, "é a percepção pelo leitor de relações entre uma obra e outras, que a precederam ou a sucederam", chegando até a identificar, em sua abordagem, a intertextualidade, assim como a transtextualidade, à própria literariedade: "A intertextualidade é [...] o mecanismo próprio da leitura literária. De fato, ela produz a significância por si mesma, enquanto que a leitura linear, comum aos textos literários e não-literários, só produz o sentido.".

Desse modo, Genette (2010) quer significar que as diversas formas de transtextualidade são ao mesmo tempo aspectos de toda textualidade e, potencialmente e em graus diversos, das categorias de textos: todo texto pode ser citado e, portanto, tornar-se citação, mas a citação é uma prática literária definida, que transcende evidentemente cada uma de suas performances e que tem suas características gerais. 


\title{
As laçadas de Colasanti
}

O texto de Colasanti (2012) levou-nos ao entendimento daquilo que Genette (1982) denomina um hipertexto e seu hipotexto.

"A moça tecelã" de Colasanti (2012) também aproximou-nos do "Manual de pintura e caligrafia", de Saramago (2001), pois o tear é a máquina na qual se produz o texto, através das linhas urdidas pelo movimento da lançadeira, realizado pelo produtor, uma vez que Saramago espelha o pintor e o escritor.

"Acordava ainda no escuro, como se ouvisse o sol chegando atrás das beiradas da noite. E logo sentava-se ao tear." (COLASANTI, 2012, p. 11). Eis o tear, que remete às moiras gregas, as quais manipulavam o fio, trabalhavam-no e cortavam-no, figuradamente, o movimento, a vida e a morte:

\begin{abstract}
Hesíodo faz delas filhas da Noite (embora também apareçam como filhas de Zeus e Têmis e irmãs das Horas) e as apresenta como três irmãs, cujos nomes, Cloto (aquela que fia), Láquesis (aquela que destina os lotes) e Atropo (a inflexível), reúnem diferentes aspectos desses espíritos. Assim, o conteúdo da vida individual depende da vontade de Láquesis; o momento da morte coincide com aquele em que Cloto corta o fio que está girando; e o indivíduo nada pode influenciar nas decisões dessas deusas. À medida que a dependência divina do homem foi ajustando-se à mentalidade determinista, a imagem das Moiras tornou-se cada vez mais abstrata. ${ }^{7}$ (MARTINEZ et al., 1995, p. 438-439, tradução nossa).
\end{abstract}

Isto foi o nosso primeiro contato com o palimpsesto: a transtextualidade, hipertexto e hipotexto que levam ao processo de criação do texto "A moça tecelã", como se pode observar na passagem a seguir, cujos hipotextos remetem às Moiras ${ }^{8}$ e ao processo de criação bíblico:

\footnotetext{
7 No original: "Hesíodo las hace hijas de la Noche (aunque aparecen también como hijas de Zeus y Temis y Hermanas de las Horas) y las presenta como tres Hermanas, cuyos nombres, Cloto (la que hila), Láquesis (la que asigna los lotes) y Átropo (la inflexible), recogen distintos aspectos de estos espíritus. Así, el contenido de la vida individual depende de la voluntad de Láquesis; el momento de la muerte coincide con aquel en que se rompe e hilo que va hilando Cloto; y el individuo no puede influir en absoluto sobre las decisiones de estas diosas. A medida que se fue racionalizando dentro de la mentalidade determinista esta dependencia divina del hombre, la imagen de las Moiras fue haciéndose cada vez más abstrata."
}

8 Cloto ( $K \lambda \omega \theta \omega \dot{;}$; klothó) em grego significa "fiar". Segurava o fuso e tecia o fio da vida. Láquesis ( $\Lambda a ́ \chi \varepsilon \sigma \sigma \zeta$; láchesis) em grego significa "sortear". Puxava e enrolava o fio tecido. Átropos ("Атропоৎ; á-tropos) em grego significa "afastar", ela cortava o fio da vida. 
Deus, a seguir, disse: "Façamos o homem à nossa imagem, à nossa semelhança [...]" (Gn 1, 26); Abençoando-os, Deus disse-Ihes: "Crescei e multiplicai-vos, enchei e dominai a terra. [...]" (Gn, 1, 28); O Senhor Deus disse: "Não é conveniente que o homem esteja só; vou dar-lhe uma auxiliar semelhante a ele." (Gn, 2, 18).

Em processo demiúrgico, a moça tece:

Mas, tecendo e tecendo, ela própria trouxe o tempo em que se sentiu sozinha, e pela primeira vez pensou como seria bom ter um marido ao lado.

Não esperou o dia seguinte. Com capricho de quem tenta uma coisa nunca conhecida, começou a entremear no tapete as lãs e as cores que the dariam companhia. E aos poucos seu desejo foi aparecendo, chapéu emplumado, rosto barbado, corpo aprumado, sapato engraxado. Estava justamente acabando de entremear o último fio da ponta dos sapatos, quando bateram à porta. [...]

Aquela noite, deitada contra o ombro dele, a moça pensou nos lindos filhos que teceria para aumentar ainda mais a sua felicidade. (COLASANTI, 2012, p. 12).

Raspando o pergaminho de Colasanti, encontramos a criação da mulher, feita por Deus a um homem sozinho no universo.

A nossa busca não parou nesse palimpsesto, "As fiandeiras"9 de Velásquez" ${ }^{10}$ (c. 1657) resumem todo processo de criação, uma vez que o pintor desenvolveu a composição em dois planos: no primeiro, está o concurso das fiandeiras, em que a deusa Athena, disfarçada de velha, está à esquerda de Aracne, de blusa branca de costas para o observador, mais três ajudantes; no segundo, um palco mais elevado exibe o tapete finalizado, ou seja, representa o tecer e o tecido, observado por espectadoras. Portanto, as fiandeiras são um texto pronto, com produção e recepção em si, além da intertextualidade com o mito "rapto da Europa". Na tela se infere o processo de transtextualidade: o hipertexto (as sequências associativas) e os hipotextos (a criação bíblica, a mitologia grega, a Odisseia e a cavalaria medieval com remissão a Cervantes).

9 "La fábula de Aracne" (Las hilanderas). Óleo sobre tela, 222,5 x 293cm. Museu do Prado, Madri.

10 VELÁZQUEZ, Diego Rodríguez de Silva y (1599-1660). Foi um pintor espanhol do período barroco e principal artista da corte do rei Filipe IV de Espanha. 
Retomando o processo de raspagem - leitura palimpsestuosa, vamos verificar que o hipertexto de Velásquez para a composição de "As fiandeiras", situada no palco mais elevado onde está o tapete pronto, tem por origem o hipotexto materializado na tela "O Rapto de Europa"11, de Ticiano ${ }^{12}$ (1562), uma das obras-primas do pintor italiano, e faz parte de um conjunto de telas célebres do artista (Poesies), baseadas nas "Metamorfoses" de Ovídio, feitas para o rei da Espanha, Filipe II. Ela mostra o momento em que Europa é raptada por Júpiter, que toma a forma de um manso touro branco, levando-a a subir em suas costas; no alto da composição, dois cupidos sobrevoam a dupla, portando arcos e flechas.

Mas como dizia Borges, existe um TEXTO e um AUTOR.

Linha clara, para começar o dia. Delicado traço cor da luz, que ela ia passando entre os fios estendidos, enquanto lá fora a claridade da manhã desenhava o horizonte.

Depois lãs mais vivas, quentes lãs iam tecendo hora a hora, em longo tapete que nunca acabava. [...]

Tecer era tudo o que fazia. Tecer era tudo o que queria fazer. (COLASANTI, 2012, p. 11-12).

A atividade da moça era construir e produzir um texto por meio do tear. Retomando o mito das Moiras, a moça tecelã exerce a função das três moiras, uma vez que ela escolhe os fios de lã e as cores; tece e corta: "Só esperou anoitecer. [...] Desta vez não precisou escolher linha nenhuma. Segurou a lançadeira ao contrário e, jogando-a velozmente de um lado para outro, começou a desfazer seu tecido." (COLASANTI, 2012, p. 13). Aqui termina o hipertexto.

Entretanto, a tecelã senta-se novamente ao tear e põe-se a criar um outro hipertexto, desta vez por transformação: "Então, como se ouvisse a chegada do sol, a moça escolheu uma linha clara. E foi passando-a devagar entre os fios, delicado traço de luz, que a manhã repetiu na linha do horizonte." (COLASANTI, 2012, p. 14). Assim, com as mesmas linhas e as mesmas cores passa a construir outro hipertexto, desta vez por transformação. Deste modo, surge outro hipertexto, uma vez que o anterior, pelo processo de desconstrução do texto, passa a ser hipotexto.

11 "The Rape of Europa". Óleo sobre tela, 178 × 205 cm. Isabella Stuart Gardner Museum, Boston, EUA.

12 Tiziano Vecelli, conhecido por Ticiano (1488/90-1576). Foi um pintor italiano renascentista. 
Voltamos ao texto bíblico para buscar na primeira Carta aos Coríntios o significado da comunicação: "Assim vós: quando vossa língua não profere senão palavras indistintas, como se compreenderá o que dizeis? Falareis ao vento. Existem, no mundo, não sei quantas espécies de línguas, e nada sem linguagem." (I Cor 14, 9-10). A linguagem, como se pode observar, é a massa criadora e produtora do texto.

\section{A proposta de Genette}

Após tais considerações, vamos esclarecer a proposta palimpsestuosa de Genette (1982), assim denominada por Lejeune, a tipologia do hipertexto e do hipotexto, seja por transformação ou por imitação.

Ao tratar do palimpsesto, Genette (1982) informa ter feito um percurso por diversos tipos de hipertextos muito ao acaso e a uma rede de preferências, segundo ele, da qual seria o pior juiz.

Nessa caminhada, o teórico francês reafirma a pertinência da distinção entre dois tipos de fundamentos de derivação hipertextual, que são a transformação e a imitação. Embora admita que se possa confundi-los, questiona se a relação de uma obra com seus "textos preliminares" estaria no domínio da transtextualidade. Conclui que não, tendo em vista que a relação genética de um texto se reporta a uma prática de autotransformação, por ampliação, por redução ou por substituição. Com isso, chega à definição de hipertextualidade, ou seja, "toda situação redacional funciona como um hipertexto em relação à precedente, e como um hipotexto em relação à seguinte."13 (GENETTE, 1982, p. 447).

Como crítico literário, Genette (1982) sugere uma divisão possível entre dois tipos de funções do texto, das quais uma é de ordem prática ou sociocultural, aquela que predomina nas práticas como resumo descritivo, a tradução, a prosificação, nas diversas formas de transmodalização como adaptação teatral ou cinematográfica, e na maior parte das sequências e das continuações. A outra função é a estética, que é propriamente criativa, que ocorre quando um escritor se apoia em uma ou várias obras anteriores para elaborar aquela na qual investirá seu pensamento ou sua sensibilidade de artista, como é o caso de "A moça tecelã", de Colasanti (2012), já que se trata de uma transposição temática, através da criação.

13 No original: "[...] I'hypertextualité telle que définie ici: tout état rédactionnel fonctionne comme un hypertexte par rapport au précédent, et comme un hypotexte para rapport au suivant". 
Assim, para Genette (1982, p. 448) "a hipertextualidade é uma prática transgenérica, que compreende alguns gêneros ditos 'menores', como a paródia, o travestimento, o pastiche, o digest, etc., e que atravessa todos os outros."14

Esses gêneros são fortemente codificados e marcados por uma grande impressão de imitação genérica, às vezes até de pura ficção romanesca. Nesse sentido, Genette (1982, p. 449) observa alguns traços de evoluções, de mutações, de aparecimentos e desaparecimentos, de investimentos diacronicamente privilegiados:

\begin{abstract}
A paródia, por exemplo, ocorre, certamente, em todos os tempos, mas o travestimento parece esperado no século XVII. A charge precede aparentemente o pastiche, mas só se constitui em gênero profissional no fim do século XIX. O antirromance nasceu com o Quixote. A continuação é evidentemente uma prática mais antiga e clássica do que moderna. A transposição, e talvez mais genericamente a hipertextualidade, responde certamente mais a uma atitude estética ao mesmo tempo clássica e moderna, com um eclipse relativo - pelo menos na França - durante a primeira metade, romântica e realista, do século XIX; mas um certo espírito do século XVIII sobreviveu manifestadamente na obra de certos autores como Nodier, Janin, Merimée, Stendhal, e mesmo frequentemente Balzac, e vimos ressurgir sob o Segundo Império uma atitude de brincadeira cultural que a posteridade não extinguiu. ${ }^{15}$
\end{abstract}

No entanto, Genette não pretende dizer que toda modernidade seja hipertextual, tampouco reduzir à hipertextualidade todas as formas de transtextualidade, visto que a distinção mais evidente da metatextualidade, que nunca é em princípio de ordem narrativa ou dramática, enquanto o hipertexto é quase sempre ficcional, ficção derivada de uma outra ficção, ou de um relato de acontecimento real.

\footnotetext{
14 No original: "[...] I'hypertextualité est une pratique transgénérique, qui comprend quelques genres dits 'mineurs' comme la parodie, le travestissement, le pastiche, le digest, etc., et qui traverse tous les autres".

15 No original: "La parodie, par exemple, est sans doute de tous les temps, mais le travestissement semble avoir attendu le Xlle siècle. La charge precede apparemment le pastiche, mais ne se constitue en genre professionnel qu'à la fin du XIXe siècle. L'antiroman naît avec le Quichotte. La continuation est évidemment une pratique plus ancienne et classique que moderne. La transposition, et peut-être plus généralement l'hypertextualité, répond sans doute advantage à une attitude esthétique à la fois classique et modern, avec une eclipse relative - au moins en France - pendant la première moitié, romantique et réaliste, du XIXe siècle; mais un certain espririt du XVIIle se survit manifestement chez des auteurs comme Nodier, Janin, Mérimée, Stendhal, et meme souvent Balzac, et nous avons vu resurgir sous le Second Empire une attitude de badinage culturel dont la postérité n'est pas éteinte.".
} 


\section{Considerações finais}

"A moça tecelã" também remete à Odisseia (HOMERO, 2000), em que Penélope, esposa de Ulisses, esperava pelo marido que fora convocado para lutar na Guerra de Troia. Todavia, os anos passavam e não havia notícia dele, se estaria vivo ou morto. Então o pai de Penélope sugeriu que sua filha se casasse novamente. Penélope, fiel ao seu marido, recusou, dizendo que esperaria a sua volta. Diante da insistência do pai e para não descontentá-lo, resolveu aceitar a corte dos pretendentes à sua mão, impondo a condição de que o novo casamento somente se realizaria depois que terminasse de tecer um sudário para Laerte, pai de Ulisses. Com esse estratagema, ela esperava adiar a boda o máximo possível. Então, durante o dia, aos olhos de todos, tecia seu longo tapete, e à noite, secretamente, ela desfazia todo o trabalho. Com essa referência, pode-se inferir que o texto, passo a passo, expõe o processo de criação ao construir a narrativa, jogando com vários hipotextos, trabalhando o espaço, o tempo e a diegese, conforme se infere em Colasanti (2012):

- "Linha clara para começar o dia [...] desenhava o horizonte." (p. 11) [aspecto do tempo];

- "Se era forte demais o sol [...] colocava na lançadeira grossos fios cinzentos [...]" (p. 11) [domínio do tempo];

- "Leve, a chuva vinha cumprimentá-la à janela" (p. 11) [domínio do tempo];

- "Assim, jogando a lançadeira [...] passava os seus dias." (p. 11) [domínio do tempo; em suma, esse domínio é o tecer, o fazer a produção do texto];

- "Mas, tecendo e tecendo, ela própria trouxe o tempo [...]" (p. 12) [idem];

- "[...] longo tapete que nunca acabava." (p. 11) [remete à Penélope, na Odisseia].

O texto de Colasanti (2012) "A moça tecelã" é uma fotografia de um processo de produção com suas relações com hipotextos, que é um método de criação. Em se tratando de produção, transcrevemos o primeiro e o último enunciado: 
Acordava ainda no escuro, como se ouvisse o sol chegando atrás das beiradas da noite. E logo sentava-se ao tear. (p. 11). [...]

Então, como se ouvisse a chegada do sol, a moça escolheu uma linha clara. E foi passando-a devagar entre os fios, delicado traço de luz que a manhã repetiu na linha do horizonte. (p. 14).

É um texto com abertura e fechamento e a história se passa no ínterim dessa duração. E, mais, o texto, entre o abrir e o fechar, traz uma história que pode ser estudada através do palimpsesto, no qual encontramos todos os hipotextos costurados.

Através do palimpsesto de Genette, pudemos adentrar na produção do texto, uma vez que ele mesmo se conta: através da transtextualidade: hipertexto e hipotexto. "Tecer era tudo que fazia. Tecer era tudo o que queria fazer." (COLASANTI, 2012, p. 12).

Assim, embora cada texto seja único, o surgimento do significado só é possível pela relação deste texto único com outros textos. O significado é construído no modo transtextual. Um nunca é totalmente "um"; é o duplo de todos os outros que o constituem, num processo autoral criativo.

Recuperando o início deste artigo, o espanhol Bernárdez (1982) fez o levantamento dos teóricos do texto, enquanto o francês Genette trabalha com a transtextualidade e publica seu Palimpsesto (1982).

O fio condutor de Genette é a transtextualidade, com isso vai à busca do arquitexto e chega ao palimpsesto. Ora, se ele define o que é palimpsesto referencializando no sentido da palavra raspada - texto sob texto, permite que a palavra de um texto esteja sempre remetendo a um outro texto; com isso, vai marcar os hipotextos e os hipertextos. Ainda é necessário nos ocuparmos da hipertextualidade, que tem em si mesma o mérito específico de relançar constantemente as obras antigas em um novo circuito de sentido.

Quando Lejeune (1980) fala em leitura palimpsestuosa vai trabalhar com o mergulho no texto, visto que não é plana, superficial, mas de profundidade. E na profundidade se vai encontrar a produção de um texto.

Não buscamos a diegese, mas sim como se constrói a diegese, ou seja, discutimos a construção do sentido de um texto, que resulta da conjugação de forma e conteúdo, bem como da coesão e da coerência; enfim, da linguagem. 
Fechando nossa ideia, retornamos a Borges (apud GENETTE, 2010, p. 147) para firmar que existe um texto e um autor:

\begin{abstract}
Assim se completa a utopia borgesiana de uma Literatura em transfusão perpétua - perfusão transtextual -, constantemente presente em si mesma na sua totalidade e como Totalidade, cujos autores todos são apenas um, e todos os livros são um vasto Livro, um único Livro infinito. A hipertextualidade é apenas um dos nomes dessa incessante circulação dos textos sem a qual a literatura não valeria a pena.
\end{abstract}

Retomando a citação de Genette acima de que "a hipertextualidade é apenas um dos nomes dessa incessante circulação dos textos", a leitura relacional ou palimpsestuosa, proposta por Lejeune, configura a produção e a criação estética e criativa de textos como foi observado em "A moça tecelã", de Marina Colasanti. Por que o chamamos de um texto instigante? Primeiramente pelo qualificativo "tecelã", ligado ao processo de tecer e, consequentemente, à produção do texto. Segundo, pela sua produção que nos levou ao palimpsesto de Genette. Terceiro motivo, por ter nos levado a uma leitura relacional, e, finalmente, à linguagem lírica, dramática e trágica: "Mas, tecendo e tecendo, ela própria trouxe o tempo em que se sentiu sozinha." [...] "Não esperou o dia seguinte." (COLASANTI, 2012, p. 12).

Ainda refletindo sobre a criação e produção do texto de Colasanti (2012), o uso da teoria de Genette ajusta-se a ele, posto que o texto desconstruído constrói um outro texto, produzindo, desse modo, o entretexto. Observe-se o início do texto: "Acordava ainda no escuro [...] E logo sentava-se ao tear." (p. 11). Uma vez descontruído, sua matéria é retomada no outro: "Então, como se ouvisse a chegada do sol, a moça escolheu uma linha clara. E foi passando-a devagar entre os fios, delicado traço de luz, que a manhã repetiu na linha do horizonte." (14). Como Genette (2010, p. 7) define o palimpsesto: "o antigo [o texto desconstruído] sob o novo [o texto a ser construído]".

\title{
REFERÊNCIAS
}

BÍBLIA SAGRADA. Edição da Palavra Viva. Missionários Capuchinos de Lisboa. C.D. Stampley Inc., 1974.

BERNÁRDEZ, E. Introducción a la lingüística del texto. Madrid: Espasa-Calpe, 1982.

BORGES, J. L. Ficções. Tradução Carlos Nejar. 3. ed. São Paulo: Globo, 2001. 
COLASANTI, M. A moça tecelã. In: COLASANTI, M. Um espinho de marfim e outras histórias. Porto Alegre: LP\&M, 2012. p. 11-14.

GENETTE, G. Palimpsestes: la litterature au second degre. Paris: Éd. du Seuil, 1982.

GENETTE, G. Palimpsestos: a literatura de segunda mão. Extratos traduzidos por Cibele Braga et al. Belo Horizonte: Viva Voz, 2010.

HOMERO. Odisseia. Tradução Odorico Mendes. Antônio Medina Rodrigues (org.). Prefácio Haroldo de Campos. São Paulo: Ars Poetica / EDUSP, 2000.

KRISTEVA, J. Semeiotike: recherches pour une sémanalyse. Paris: Seuil, 1969. (Tel Quel).

LEJEUNE, P. Je est un autre: l'autobiographie, de la littérature aux médias. Paris: Seuil, 1980.

MARTINEZ, C. F. et al. Diccionario de la mitologia clasica 2. Madrid: Alianza Editorial, 1995.

RIFFATERRE, M. La production du texte. Paris: Seuil, 1979. (Poétique).

SARAMAGO, J. Manual de pintura e caligrafia. São Paulo: Companhia das Letras, 1992.

TICIANO (Tiziano Vecelli). The Rape of Europa, 1562. Óleo sobre tela (178 cm x $205 \mathrm{~cm}$ ). Boston, EUA: Isabella Stuart Gardner Museum.

VELÁSQUEZ, D. O mito de Aracne (As fiandeiras), c. 1657. Óleo sobre tela (222,5 cm x 293 $\mathrm{cm})$. Madrid: Museu do Prado. 